\title{
Stomatal responses of pearl millet (Pennisetum americanum [L.] Leeke) to leaf water status and environmental factors in the field
}

\author{
I. E. HENSON*, G. ALAGARSWAMY, F. R. BIDINGER \& V. MAHALAKSHMI *Plant Breeding Institule. \\ Maris Lane, Trumpington, Cambridge CB2 2LQ and International Crops Research Institute for the Scmi-Arid \\ Tropics, Patancheru P.O., Andhra Pradesh 502 324. India
}

Received 27 April 1981; accepted for publication 10 June 1981

\begin{abstract}
Factors affecting stomatal conductance $\left(g_{1}\right)$ of pearl millet (Penniserum americanum [L.] Lecke), oultivar BJ 104, were examined in the field in India during the dry season.

Diurnat changes in $g_{1}$ were evaluated for upper expanded leaves at flowering on two occasions using plants subjected to varying degrees of water stress. Except for the most severely stressed treatment, diurnal changes in $g_{1}$ closely matched changes in irradiance $(I)$, the promotive effect of which largely overcame opposing influences on $g_{1}$ of increasing atmospheric vapour pressure deficit, and decreasing leaf water and turgor potentials $\left(\psi, \psi_{p}\right)$.

Two main effects of water stress on $g_{1}$ were evident: (i) a decrease in the amplitude of the mid-day peak in $g_{1}$, and (ii) a decrease in the time over which high $g_{1}$ was maintained, resulting in carly (mid-day) closure and hysteresis in the relationship between $g_{1}$ and $l$.

Leaf conductance was greatest for upper leaves and decreased down the canopy. At equivalent depths in the canopy $g_{1}$ was higher in flowering than in photoperiodically-retarded plants of the same age. The magnitude of water stress-induced stomatal closure increased dowo the plant, and was more marked in retarded than in flowering plants.

Within individual stress treatments $\psi$ of upper leaves decreased linearly as Iranspiration flux increased/It is concluded that stomatal behaviour of upper leaves of pearl millet at flowering largely operates to maximize assimilation rather than to minimize water loss.
\end{abstract}

K'ey-words: Pennisetum americanum (L.) I.ecke; Gramineae; pearl millet; stomatal conductance; water siress.

\section{Introduction}

Pearl millet (Pennisetum americanum [L.] Leeke, syn. $P$. typhoides [Burm.f.] S. and H.) is commonly regarded as one of the most drought-resistant cereals in cultivation (Catherinet et al., 1963; Cochemé \&

Correspondence: Dr I. E. Henson, Plant Breeding Institute, Maris Lane, Trumpinglon. Cambridge CB2 2LQ, England.

0140-7791/82/0200-0065\$02.00

(c) 1982 Blackwelr Scientific Publications
Franquin, 1967: Arnon, 1972: Perraris, 1973). It is grown extensively in semi-arid regions where insulticient and erratic rainfall constitutes a major limitation to crop growth. Despite its reputed ability to grow and produce grain under such conditions, the physiological basis for drought-resistance in pearl millet is little understood, and has been the subject of few investigations (Begg at al., 1964; ICRISAT, 1977. 1978, 1980); Black \& Squire, 1979; Gregory, 1979; Gregory \& Squire, 1979; Squire. 1979).

Stomatal closure during water stress is a major factor mitigating the effects of drought. In a pot experiment with young pearl millet plants (Henson el al., 1981a) stomatal conductance $\left(g_{1}\right)$ was observed to decline rapidly with declining $\psi$. By contrast, in field experiments (Henson "1 al., 198I; ICRISAT, 1980), stomatal closure in response to water stress was only partial despite $\psi$ falling to values considerably lower than those required to induce almost complete stomatal closure in the pot-grown plants. The reasons for these differences between plants grown in pots and in the field. which have been observed frequently in several species (Turner, 1974a; Begg \& Turner, 1976) are not fully understood, although the stage of plant development (Ackerson \& Kreig, 1977: Morgan. 1977) and the degree of 'stress hardening' experienced by the plants (McKree, 1974: Brown, Jordan \& Thomas, 1976) probably both contribute.

In order to characterize further the stomatal behaviour of pearl millet under conditions in the field. experiments were conducted at ICRISAT (International Crops Research Institute for the Semi-Arid Tropics) Centre in India during the 1980 dry season (Jan-April). By obtaining information on stomatal responses to changing environmental factors under natural climatic conditions, it was hoped to obtain an insight in to the strategy normally adopted by the plant for coping with water shortage.

\section{Materials and methods}

Plant culture

Seeds of pearl millet (Pennisetum americanum [L.] 
Leeke) cultivar BJ 104, were direct sown in late January or early February in rows $0.75 \mathrm{~m}$ apart on slightly raised ridges on either a medium $(75.90 \mathrm{~cm})$ or a deep $(120 \mathrm{~cm})$ alfisol soil at two sites on the ICRISAT farm, near Hyderabad, India (17 30' north). Plants were subsequently thinned to about $10 \mathrm{~cm}$ apart within rows. All rows were initially irrigated by flooding between ridges to ensure establishment of the seedlings. The nature and frequency of subsequent irrigations varied according to the treatments imposed, as described below.

Experimental design, treatments, and sampling procedure's

Diurnal studies. Plants were sampled from two sites on the ICRISAT farm, both $43 \mathrm{~d}$ after sowing (DAS). Site I plots on a deep alfisol soil included both fully furrow-irrigated plots and plots which received no further irrigation after stand establishment, resulting in a control and a 'medium'-stress treatment with minimum mid-day $\psi$ at sampling of 0.66 and -1.17 MPa respectively. Plants were flowering when sampled. The penultimate leaf (i.e. the leaf below the flag leaf) was taken. There were three replicate plots per treatment and leaves were sampled from two randomly selected plants within each plot. Samipling commenced just prior to dawn (c. 6.0) Indian standard time) and continued at $60-90 \mathrm{~min}$ intervals until just after dusk (c. 19.00).

At site 2, on a medium depth alfisol, plants were sampled at three positions along a water supply gradient established using a line of overhead rotary sprinklers (Hanks et al., 1976). Plant rows, orientated parallel to the sprinkler line, received amounts of irrigation water which depended on their distance from the line. Rows close to the line (position 1) received sufficient water to recharge the profile to field capacity. These plants were about $85-90 \mathrm{~cm}$ tall and in full flower at the time of sampling. having produced $c$. 31.5 visible panicles per $\mathrm{m}$ length of row. Plants in rows some $11 \mathrm{~m}$ from the sprinkler line (position 2) were shorter $(63 \mathrm{~cm})$ and produced fewer panicles $(25.0$ per $\mathrm{m}$ ), while in rows at $14 \mathrm{~m}$ (position 3), plants were only $44 \mathrm{~cm}$ tall and had only 13.2 panicles per m. Plants in these three positions were estimated to have received 150,62 and $30 \mathrm{~mm}$ irrigation water respectively, in addition to that given initially to ensure stand establishment. On the day of sampling $(8 \mathrm{~d}$ after the last irrigation) plants in the three positions had minimum mid-day $\psi$ of $-1.74,-2.14$ and $-2.90 \mathrm{MPa}$ respectively. Sampling procedure was as at site 1, except that where panicles had not yet emerged the youngest fully emerged leaf and not the penultimate leaf was selected.

Leaf position. Vertical profiles within the canopy in $g_{1}$, $\psi$ and $\psi_{r}$ were investigated using plants grown either with full (furrow) irrigation or with irrigation witheld after the early vegetative stage. A photoperiodic treatment was superimposed on the irrigation treat- ments, with half of each plot receiving the prevailing short days (SD; 11.5 to $13 \mathrm{~h}$ light per day), and half receiving $16 \mathrm{~h}$ photoperiods (LD) by extending the natural daylength with light from overhead incandescent lamps. Extension of the photoperiod retarded flower initiation by $18 \mathrm{~d}$, and at the time of sampling (50) and 51 DAS) SD plants were in full flower while LD plants had no panicles visible (although stem extension had commenced).

Leaves were sampled from six randomly-selected plants along a single row, at four positions up the plant, between 11.00 and $13.00 \mathrm{~h}$ avoiding those portions of the SD sub-plots adjacent to the LD sub-plots which were subject to light spill-over. The flag leaf was sampled from flowering plants, and the uppermost fully-expanded leaf from non-flowering plants.

\section{Measurements of stomatal conductance and leaf water status}

Leaf conductance $\left(g_{1}\right)$ was measured using an automatic diffusive resistance porometer (Delta-T Devices, Burwell, UK). The instrument was calibrated using a series of standard resistance plates just before and just after each set of test measurements. During measurements the instrument was shaded from direct sunlight. Measurements by the instrument of 'cup' and leaf temperature differed on average by less than $0.6 \mathrm{C}$. Both leaf surfaces were monitored at a mid position along the leaf. Stomatal resistances $\left(\mathrm{s}^{\mathrm{cm}}{ }^{1}\right)$ were calculated from the appropriate calibration curve and converted subsequently to conductances ( $\mathrm{cm} \mathrm{s}$ '). The conductance of each surface was summed to give a total $g_{1}$ for the leaf.

Following conductance measurements the leaf was enclosed in moist muslin wrapping, excised, and the leaf water potential $(\psi)$ determined using a pressure chamber. A longitudinal half of each leaf was immediately frozen using solid $\mathrm{CO}_{2}$ and subsequently used to determine solute potential $\left(\psi_{\mathrm{s}}\right)$ and, by derivation, turgor (pressure) potential $\left(\psi_{\mathrm{p}}\right)$, as described elsewhere (Henson et.al., 1982).

\section{Environmental measurements}

Standard meterological data were obtained from a weather station on the ICRISAT farm, about $1000 \mathrm{~m}$ from the experimental sites. During diurnal sampling, measurements were also made within the crop area. Total irradiance $(I)$ was measured at 30 min intervals using a pyranometer sensor located above the crop and linked to an integrator (Lambda Instrument Co., Nebraska, USA). Wet and dry bulb temperatures were recorded every $15 \mathrm{~min}$ using an Assman type psychrometer attached to a chart recorder (Cambridge Instruments Ltd., UK), these instruments being enclosed in a Stevenson screen.

Leaf temperatures were determined during diurnal sampling using an infra-red thermometer (Barnes Engineering Co., Stamford, Connecticut). Prior to 

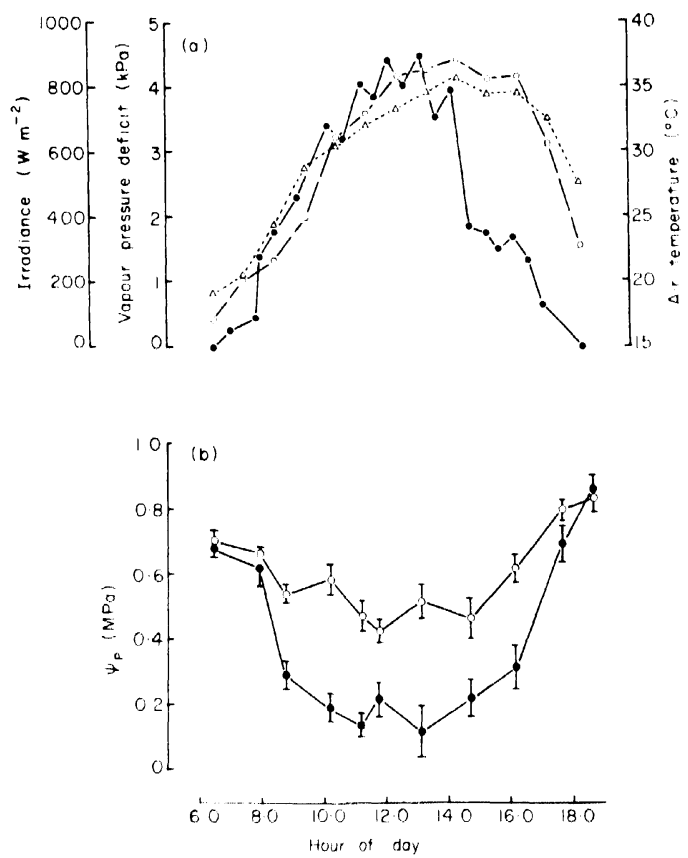

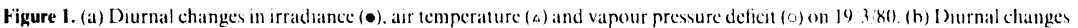

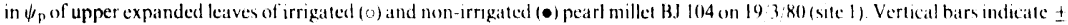
s.c. $(n-6)$.

sampling each plot, the thermometer calibration was checked against a standard calibrating device supplied by the manufacturers.

\section{Results}

\section{Diurnal changes in conductance}

Site I, control versus moderate stress. On the day of measurement (19.3.80, 43 DAS) climatic conditions normal for the season prevailed, with high mid-day irradiances and high afternoon air temperatures and atmospheric vapour pressure deficits (Fig. la). Imbalance between water uptake and water loss led to a decline at mid-day in leaf $\psi, \psi$, and $\psi_{\mathrm{p}}$, with $\psi_{\mathrm{p}}$ dropping 0.3-0.4 MPa lower in non-irrigated than in irrigated plants (Fig. Ib). (For the diurnal changes in $\psi$ and $\psi$, see Henson et al. 1982.) Despite these diurnal reductions in bulk leaf potentials, adaxial $g_{1}$ increased in both treatments reaching a peak near to mid-day before declining (Fig. 2b). There was no such consistent change with time in abaxial $g_{1}$, and within treatments the effect of sampling time was not significant. There was, however, a highly significant $(P<0.001)$ reduction in mean abaxial $g_{1}$ due to water stress (Fig. 2a). Though the mean adaxial $g_{1}$ of stressed plants was also reduced. this reduction was only significant at $P<0.05$.

Visual inspection of the data (Figs la, 2b) suggested that adaxial (and also total) $g_{1}$ closely followed changes in $I$. This impression was confirmed following correlation and multiple linear regression (MLR) analysis with all 'internal' $\left(\psi, \psi_{p}, \psi\right.$, leaf temperature $)$ and environmental $(I$, leaf-to-air vapour pressure deficit [lvpd], air temperature) parameters being included as independent variables in the analysis. For the adaxial surface $62.8 \%$ (control) and $58.6 \%$ " (stressed) of the variance in $g_{1}$ could be accounted for by changes in $I$ alone, while lvpd (the next most influential variable) accounted for only 16.1 and $7.3^{\circ}$ " of the variance in $g_{1}$ when $I$ was omitted from the analysis. (However, when allowance was made for the influence of $I$, a negative effect of lvpd on $g_{1}$ was generally more evident, as shown by the change in the regression cocfficients [Table 1; also see below].) Adaxial $g_{1}$ thus closely matched $I$, and continued to increase with increasing $I$ with no evidence of saturation (Fig. 3b). The slopes of the regressions of adaxial $g_{1}$ on $I$ for control and stressed leaves did not differ significantly.

The abaxial surface was much less responsive to $I$ than the adaxial surface and was unaffected by $I$ with water stress (Fig. 3a). This led to total $g_{1}$ of stressed 


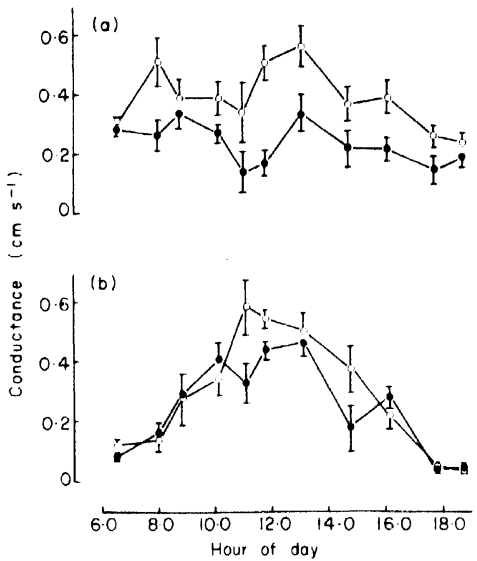

Figure 2. Diurnal changes in abaxial (a), and adaxial (b) conductance of upper expanded leaves of irrigated $(0)$ and non-irrigated $(\bullet)$ pearl millet BJ 104 on $19 / 3 / 80$ (site 1). Vertical bars indicate \pm s.e. $(n-6)$.

plants being significantly $(P<0 \cdot() 5)$ less responsive to $I$ than $g_{1}$ of irrigated plants.

Although within treatments, increasing $I$ largely negated effects on $g_{1}$ of increasing water stress, stomata were still responsive to leaf water status. Thus, when $I$ was high and essentially constant $g_{1}$ tended to be greatest in those leaves having the highest $\psi_{\mathrm{p}}$ (Fig. 4).

Site 2: 'setere' stress. Plants were again sampled 43 DAS, but on the day of sampling (7.3.80) maximum irradiance was slightly lower than for 19.3.80 and declined earlier in the afternoon due to cloud cover (Fig. 5a). Severe water stress was evident, however, as indicated by low $\psi$ and $\psi_{\text {p }}$ at mid-day (Fig. 5 b; see also Materials and methods). Changes in adaxial and abaxial $g_{1}$ are shown in Fig. 6a, b. For the plants at positions 1 and 2 in the water supply gradient changes in $g_{1}$ closely followed $I$, but for plants at position 3 receiving less water, after an initial rise, $g_{1}$ declined sharply just prior to mid-day with falling $\psi$ and $\psi_{p}$, and remained low for the remainder of the photoperiod. Maximum total conductances were lower than for control plants sampled on 19.3, but were not appreciably different from the moderately stressed treatment sampled on that date.

The two leaf surfaces responded similarly over the day (Fig. 6), with adaxial $g_{1}$ heing generally higher than abaxial $g_{1}$ as with stressed plants at site 1 . Also, as at site 1, water stress had a more significant effect in reducing mean abaxial $g_{1}(P<0.001)$ than in reducing mean adaxial $g_{1}(P<0.01)$.

The effects of water stress were evident in plots of $g_{1}$ v. I (Fig. 7a, b) which revealed (i), the 'saturation' of abaxial $g_{1}$ at an irradiance of $<250 \mathrm{~W} \mathrm{~m}^{* 2}$ and (ii),

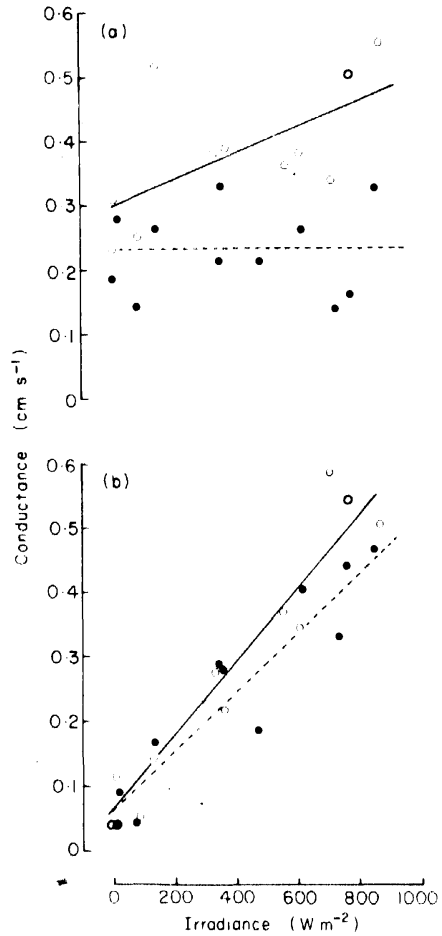

Figure 3. Relationships between abaxial (a), and adaxial (b) conductance $\left(g_{1}\right)$, and irradiance $(I)$, for upper expanded leaves of irrigated $(0)$ and non-irrigated (•) pearl millet BJ 104 on 19/3/80. Hach point is a mean of six. Lines are fitted linear regrcssions of $g_{1}$ on $I$ lor irrigated $(\ldots)$ ) and non-irrigated $(\ldots-)$ plants. For (a) $r=0.37$. significant at $P<0.05$ (irrigated) and $<0.01$, not significant (non-irrigated), for (b) $r=0.96$ (irrigated) and 0.93 (non-irrigated), both significant at $P<0.001$

hysteresis in the $g_{1}$ v. I relationship, with stomatal closure on both surfaces occurring at irradiances which sustained higher $g_{1}$ values during the opening phase before $\psi_{p}$ declined to zero. Both these latter effects were present essentially in all three treatments and were in marked contrast to responses observed at site 1 .

As with site 1 data correlation and MLR analysis confirmed the dominant effect of $I$ on $g_{1}$, with $I$ accounting for 59 and $61 \%$ of the variance in total $g_{1}$ at positions I and 2 respectively, though only $16 \%$ of the variance for severely stressed plants at position 3 . MLR analysis showed that lvpd was the factor with the most influence on $g_{1}$ after $I$. However, Ivpd had little significant effect on $g_{1}$ alone (accounting for less than $8 \%$ of the variance in total $g_{1}$ when considered independently of other variables) and regression coefficients were in general non-significant. When the effect of $I$ was allowed for by MLR (Table 1), both the 


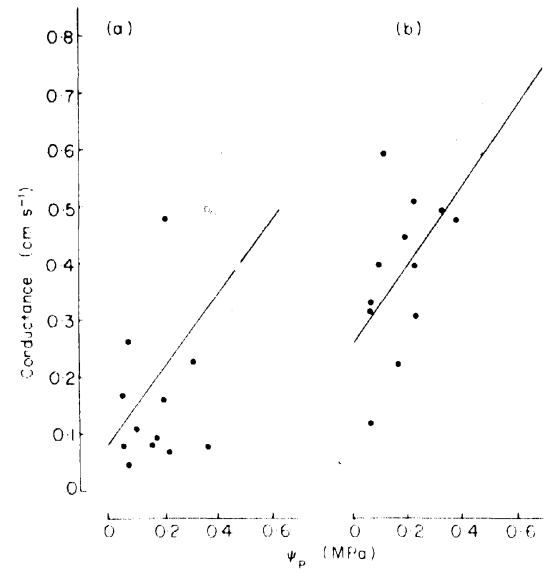

Figure 4. Relationships between abaxial (a) and adlaxial (b) conductance $\left(g_{1}\right)$, and bulk leaf $\psi_{\mathrm{p}}$, for upper expanded leaves of pearl millet BJ 104 at constant irradiance $\left(754 \mathrm{~W} \mathrm{~m}{ }^{2}\right)$ on $19 / 3 / 80$. Points represent individual leaves from irrigated $(0)$ and non-irrigated $(\bullet)$ plots. Lines are fitted linear regressions of $g_{1}$ on $\psi_{\mathrm{p}}$. For (a) $r-0.51$ $(P<0.05)$ and for (b) $r=0.65(P<0.01)$.

magnitude and significance of the regression coefficients $(\beta)$ for $g_{1}$ on Ivpd were increased, revealing a significant influence of lupd on $g_{1}$. This effect did not vary appreciably between surfaces, neither was there any general dependence of $\beta$ on the degree of water stress. This contrasts with the observations of Black \& Squire (1979) and Squire (1979) that only stomata of wellwatered millet plants responded to changes in vpd.

\section{Effects of leaf position and developmental stage}

In this experiment no consistent differences were observed in the response to water stress by the two leaf surfaces and hence only total conductances are considered.

Total $g_{1}$ of leaves at different levels within the canopy are shown in Fig. 8a, b. In general, upper leaves had higher conductances than lower ones. However, there were significant differences in $g_{1}$ down the canopy only in flowering plants (the differences for leaf position being significant at $P<0.05$ for control plants and $P<0.001$ for stressed ones).

The effect of water stress on $g_{1}$ depended both on leaf position within the canopy and stage of plant development as influenced by photoperiod (Fig. 8c). The effect of water stress on $g_{1}$ increased with increasing depth in the canopy; conductance of the upper leaf layer being least affected by stress. At equivalent depths within the canopy, stress reduced the conductance of retarded plants more than that of flowering plants. Indeed, for flowering plants there was no effect of stress on $g_{1}$ of the topmost leaf layer. It was not possible, however, from these data, to determine whether stomata of relarded plants were inherently more sensitive to stress than stomata of flowering plants. Although a greater degree of stomatal closure was evident in the former group and both groups had similar mean leaf $\psi$ (c. - 1.5 MPa; Henson et al., 1982), keaf $\psi_{n}$ was aboul $0.14 \mathrm{MPa}$ lower in retarded than in flowering plants

\section{Discussion}

\section{Irradiance}

The diurnal course of conductance in pearl millet appeared to be governed largely by changes in $I$, which modified stomatal response to water stress in a manner qualitatively similar to that observed for other crop species (Turner, 1974a; Biscoe, Cohen \& Wallace. 1976). This finding is consistent with results of earlier studies (ICRISAT, 1980), and with those of Squire (1979), who found that canopy conductance of pearl millet plants growing in drying soil was mainly related to $I$, while being unaffected by changes in vpd. In the present study inciusion of environmental factors additional to $I$ as independent variables in MLR analyses led to only small additional improvements in fit. In its effect on conductance, therefore, $I$ largely overrode opposing influences of concomitant changes in Ivpd and leaf water status. Because of this it is likely that $\psi$ and $\psi_{p}$ were to a large extent functions of $g$, rather than the converse, with low $\psi$ occurring due to high evaporation rates, resulting in turn from high $g_{1}$ combined with high lvpd. Thus, when $\psi$ was related to transpiration flux as estimated from the product of lvpd and $g_{1}$ (Kaufmann \& Hall, 1974). significant negative correlations were obtained (Fig. 9). Although the estimates of transpiration were necessarily approximations (the contribution of boundary layer resistance in determining transpiration flux not having been assessed), the data support the view that $\psi$ was a function of transpiration rate. Stomatal behaviour was thus most probably directed towards maximizing $(\mathrm{C})$. assimilation rates rather than minimizing water loss. As assimilation was not measured no conclusions can be drawn regarding 'optimal' stomatal functioning. However, one might speculate whether water use efficiency in pearl millet, unlike in $\mathrm{C}_{3}$ species, might not actually be favoured by maximizing $g_{1}$ (as concluded by Cowan (1977) to be the case for the $\mathrm{C}_{4}$ desert species Tidestromia oblongifolia). For this to be so, assimilation would have to increase with $I$ at least up to full sunlight and not be unduly limited by high temperatures or water stress. The first two conditions appear to be satisfied for millet both on the basis of laboratory studies (McPherson \& Slatyer, 1973), and, in part, by the present field results (Fig. 3).

The effect of $l$ on $g_{1}$ is generally accounted for by its effect, via photosynthesis, on intra-cellular $\mathrm{CO}_{2}$ concentration $\left(C_{i}\right)$, with low $C_{i}$ favouring stomatal opening (Raschke, 1975). For this explanation to hold in the present case it would be necessary for rates of photosynthesis sufficiently adequate to reduce $C_{i}$ (and hence 


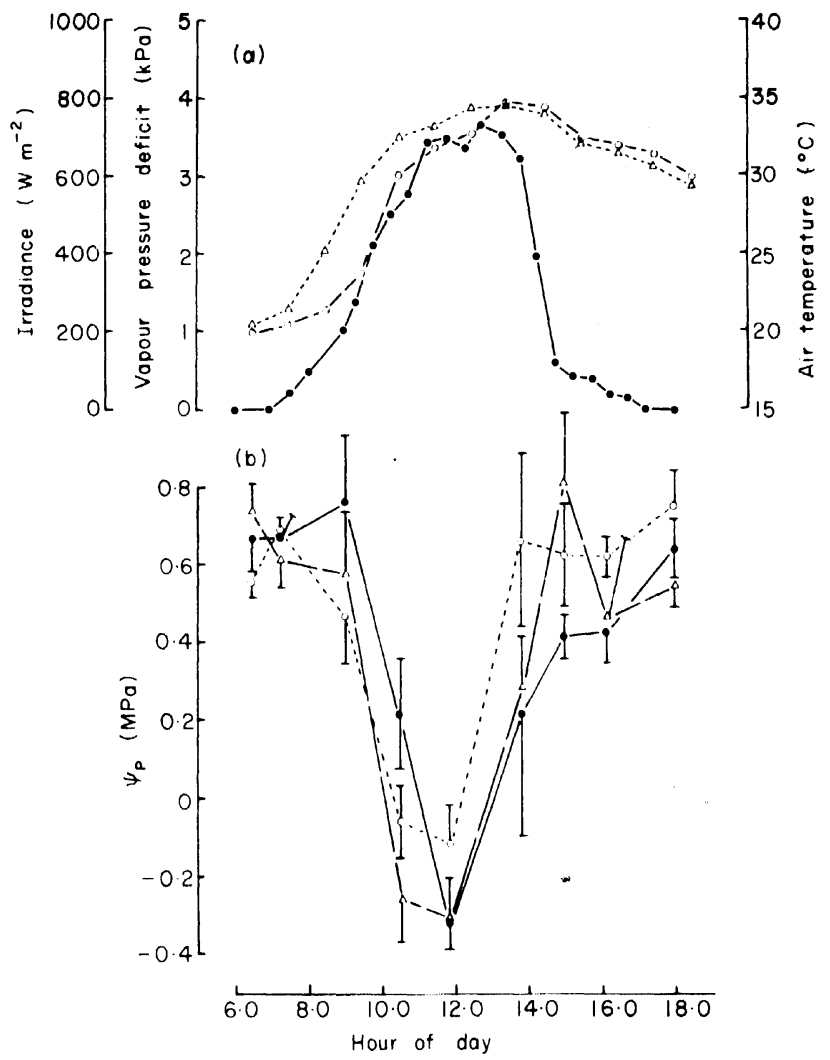

Figure 5. (a) Diurnal changes in irradiance ( $\bullet$ ), air temperature $(\Delta)$ and vapour pressure deficit $(0)(n n) 7 / 80$. (b) Diurnal changes on $7 / 3 / 80$ (site 2) in $\psi_{p}$ of upper expanded leaves of pearl millet BJ I04 grown at three positions in a water supply gradient (0. position 1; $\Delta$, position 2; $\bullet$ position 3; see text for further details). Vertical bars indicate + s.e. $(n-6)$.

increase $\left.g_{1}\right)$, to be attained despite severe internal water stress. The requisitc robustness of photosynthetic activity in pearl millet to water stress has, however, yet to be demonstrated.

One benefit to accrue from high $g_{1}$ is lowering of leaf temperature below that of the air, so lessening the chance of irreversible tissue damage at high temperatures. In the present studies (data not presented) leaf temperatures were as much as $5 \mathrm{C}$ below air temperatures at maximum conductance.

The variation in $g_{1}$ with leaf position within the canopy is most readily interpreted in terms of a vertical gradient in irradiance. Light penetration into a millet canopy was found to decrease linearly with depth (within rows) approaching extinction at about $75 \mathrm{~cm}$ below the top (Begg, 1965). Reductions in $g_{1}$ down the canopy were previously observed for pearl millet by Squire (1979), and for other crop species by Begg \& Turner (1970), Turner \& Begg (1973), Turner (1974b),
Jones (1977) and Sivakumar et al. (1979). In the present study an interaction was evident between leaf position (and therefore irradiance level) and water stress. Conductances of upper leaves exposed to full sunlight were least affected by stress, while stomatal closure occurred in response to stress more readily with increasing depth within the canopy (Fig. 8c). This response was not a result of increased stress at increasing depth, for $\psi_{\mathrm{p}}$ was similar at all leaf levels while $\psi$ actually increased down the canopy (Henson et al., 1982). Conductance was therefore inversely proportional to $\psi$. Although leaf age effects might also contribute, it is suggested that $I$ was mainly responsible for the observed $g_{1}$ profile, overriding the effects of water stress as observed on a diurnal basis, again probably via its effects on $C_{i}$. Such differential stress sensitivity between leaf layers would be expected to be of considerable advantage to the plant, as high $g_{1}$ in leaves most exposed to light would serve to ensure 

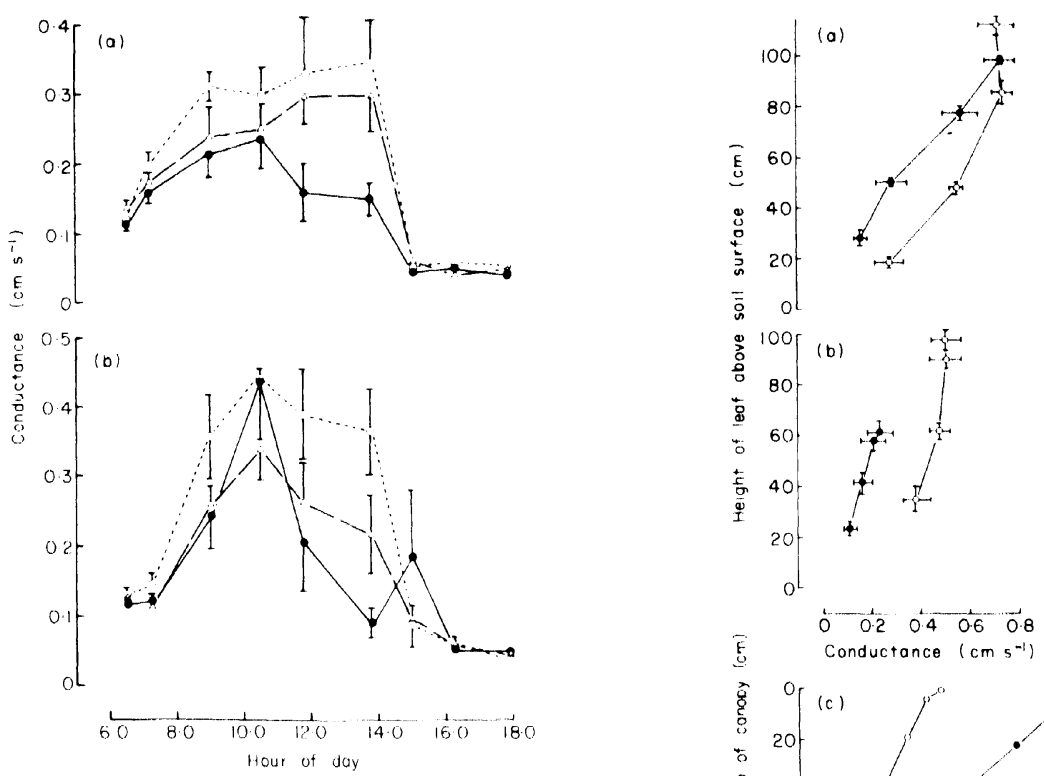

Figure 6. 1) jurnal changes on $7 / 3 / 80$ (site 2 ) in abaxial (a) and adaxial (b) conductance of upper expanded leaves of pearl millet B.I 104 grown at three positions in a water supply gradient. For explatnation of symbols see Fig. 5b. Vertical bars indicate ts.e. $(n-6)$.
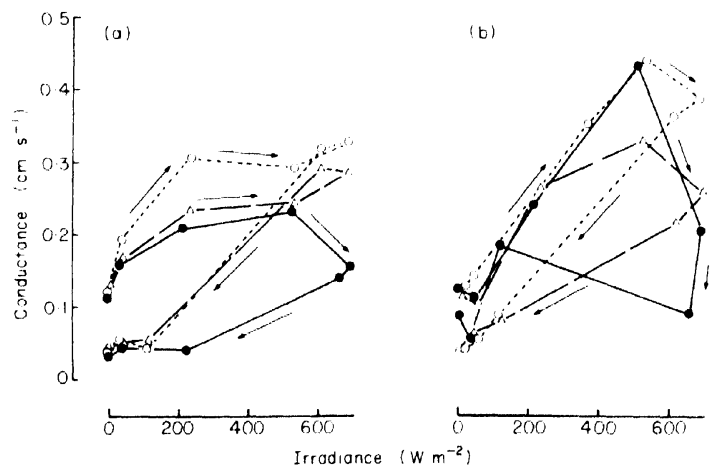

Figure 7. Relationships, on $7 / 3 / 80$ (site 1) between abaxial (a) and adaxial (b) conductance and irradiance for upper expanded leaves of pearl millet BJ 104 grown at three positions in a water supply gradient. For explanation of symbols see Fig. Sh. Arrows indicate direction of change in time.

Figure 8. Lffect of leaf position and water stresson total conductance (gl) of pearl millet B.J 104 (a) Flowering plants, changes in $g$ | witl hetght for irrigated $(O)$ and non-irrigated $(\bullet)$ plants. Bars indicate \pm s.c., $n-6$. (b) As in (a) but for photoperiodically relarded plants. (c Total $g_{1}$ of non-irrigated plants as a pereentage of total $g_{1}$ of irrigated plants at equivalent distances from the top of the canopy (relative $\left.g_{1}\right)$ for flowering $(\bullet)$ and retarded $(0)$ plants. 


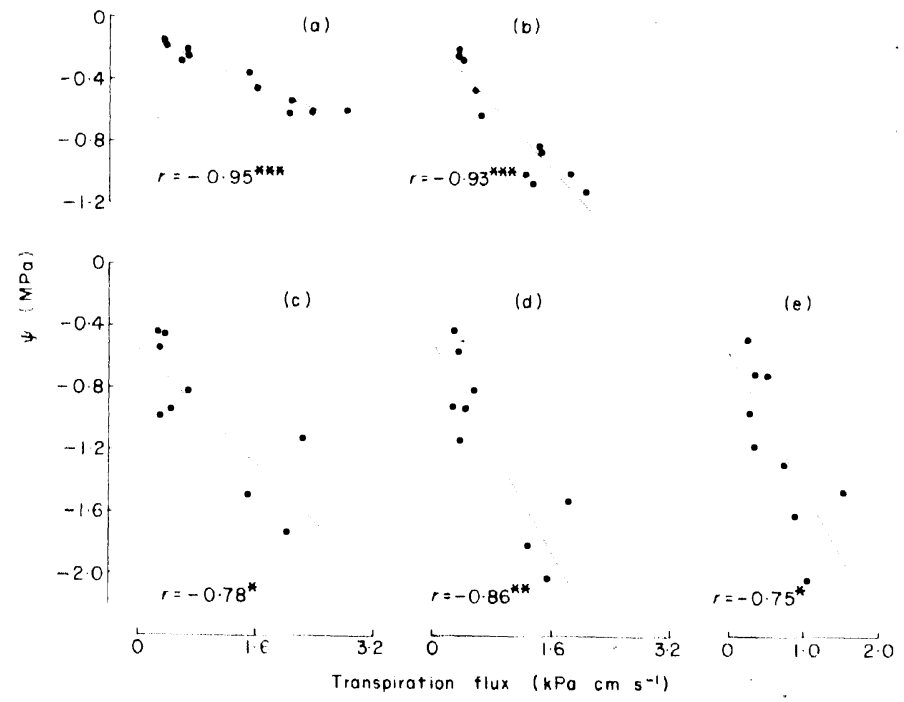

Figure 9. Relationships between leaf $\psi$ and estimated transpiration flux (lupd $\times g_{1}$ ) over the course of a day for pearl millet grown with varying soil moisture regimes. (a) and (b), irrigated and droughted plants respectively, site 1. (c), (d). (c) positions 1,2 and 3 respectively, site 2. Points are means of six and represent different sampling times as shewn in Figs $l \mathrm{~b}$ and $5 \mathrm{~b}$. Lines are fitted linear regressions. Correlation coeflicients $(r)$ are given; ${ }^{*},{ }^{* *},{ }^{* * *}$ indicate significance at $P<0.05,0.01$ and 0.001 respectively. $1 \mathrm{kPa} \mathrm{cm}$ $s^{1}=7.16 \mu \mathrm{g} \mathrm{H}_{2} 0 \mathrm{~cm}^{-2} \mathrm{~s}^{-1}$ at $30 \mathrm{C}$.

Table I. Influence of irradiance ( $I$ ) and leaf-to-iar vapour pressure deficit (lvpd) on diurnal changes in conductance $\left(g_{1}\right)$ of abaxial and adaxial leaf surfaces of pearl millet, cv. B.J 104. Data are regression coefficients, $\beta$. (where $y-\alpha+\beta x$ ) for the regression of $g$, on $l$ and $l v p d$, either computed independently or in combination using multiple linear regression analysis. Levels of significance of $\beta$ from zero are shown as: n.s., non-significant: ***, ***, significant at $\rho=0.05,0.01$ and 0.001 respectively. The units of $\beta$ are for $g_{1}$ v. $I . \mathrm{mm} \mathrm{s}^{-1} / \mathrm{W} \mathrm{m}^{-2}$; for $g_{1} \mathrm{v} . I v p d, \mathrm{cms}^{-1}$ $\mathrm{kPa}$ I.

\begin{tabular}{|c|c|c|c|c|c|c|}
\hline \multirow[b]{2}{*}{ Site } & \multirow[b]{2}{*}{ Truatment ${ }^{+}$} & \multirow{2}{*}{$\begin{array}{l}\text { L.eaf } \\
\text { surface }\end{array}$} & \multicolumn{2}{|c|}{$\begin{array}{l}\beta . \text { independent } \\
\text { regression }\end{array}$} & \multicolumn{2}{|c|}{$\beta$, multiple regression } \\
\hline & & & $g_{1} \vee 1$ & $g_{1}$ v lvpd & $g_{1} \vee I$ & $g_{1} \vee \operatorname{lvpd}$ \\
\hline \multirow[t]{3}{*}{1} & Control & abaxial & $0.201 * *$ & $0.011^{\mathrm{ti}}$ & $0.307 * * *$ & $-0.065^{*}$ \\
\hline & & adaxial & $0.579 * * *$ & $0.117^{* * * \pm}$ & $0.648 * * *$ & $\ldots 0.042 \cdots$ \\
\hline & Stressed & $\begin{array}{l}\text { abaxial } \\
\text { adaxial }\end{array}$ & $\begin{array}{l}0.0011^{\mathrm{nv}} \\
0.443^{* * *}\end{array}$ & $\begin{array}{r}-0.048^{* *} \\
0.058^{*+}\end{array}$ & $\begin{array}{l}0.131^{*} \\
0.526^{* * * *}\end{array}$ & $\begin{array}{c}-0.074^{* * *} \\
-0.047^{*}\end{array}$ \\
\hline \multirow[t]{3}{*}{2} & Position 1 & $\begin{array}{l}\text { abaxial } \\
\text { adaxial }\end{array}$ & $\begin{array}{l}0.377^{* * *} \\
0.489 * * *\end{array}$ & $\begin{array}{r}-0.0311^{11} \\
-0.027 \mathrm{~m}\end{array}$ & $\begin{array}{l}0.424 * * * \\
0.539^{* * *}\end{array}$ & $\begin{array}{r}-0.056 * * * \\
-0.056^{* * *}\end{array}$ \\
\hline & Position 2 & $\begin{array}{l}\text { abaxial } \\
\text { adaxial }\end{array}$ & $\begin{array}{l}0.317^{* * *} \\
0.306\end{array}$ & $\begin{array}{l}-0.019 \mathrm{~ns} \\
002 \mathrm{~ns}^{\circ}\end{array}$ & $\begin{array}{l}0.358 * * * \\
0.356 * * *\end{array}$ & $\begin{array}{l}-0.043 * * * \\
-0.052 * * *\end{array}$ \\
\hline & Position 3 & $\begin{array}{l}\text { abaxial } \\
\text { adaxial }\end{array}$ & $\begin{array}{l}0.139 * * * \\
0.202 *\end{array}$ & $\begin{array}{l}-0.033 * * * \\
0.029^{m !}\end{array}$ & $\begin{array}{l}0.214 * * * \\
0.280 * *\end{array}$ & $\begin{array}{l}-0.053^{* * *} \\
-0.055^{* *}\end{array}$ \\
\hline
\end{tabular}

+ For further details see text.

$\ddagger$ Note positice association. 
maximum assimilation, while stress-induced stomatal closure in leaves less favourably situated for photosynthesis would aid water conservation without unduly sacrificing assimilation capacity.

\section{Leaf water status}

Drought resulted in large changes in bulk leaf $\psi$ and $\psi_{\mathrm{r}}$ during the day. Negative $\psi_{p}$ values as found at mid-day with the more stressed treatments (Fig. 5), probably arose due to $\psi_{\mathrm{s}}$ being overestimated following mixing of cell sap and apoplastic water during extraction of sap samples (Tyrec, 1976). However, as indicated by severe wilting of the leaves, zero $\psi_{\mathrm{p}}$ was most probably attained at mid-day in these treatments, yet stomata were open (Fig. 6).

The ability of pearl millet stomata to remain open at low $\psi$ and $\psi_{\mathrm{p}}$ suggests that turgor relations between guard and subsidiary cells which govern stomatal aperture were, to a large extent, independent of bulk leaf $\psi$ or $\psi_{p}$. Generation of low $\psi_{\text {, within guard cells }}$ would be required to sustain opening in the face of low bulk leaf $\psi_{p} .11$ is suggested that the guard cells were capable of preferentially accumulating solutes, so maintaining turgor.

As the effects of diurnal changes in water status on $g_{1}$ were largely counteracted by the changes in $I$, the effects of water stress were mainly apparent as differences between treatments, either in the maximum $g_{1}$ attained (Figs $2 \& 6$ ), in the period over which high $g_{1}$ was mainlained (Fig. 6 ), or in the slopes relating $g_{1}$ to $l$ (Figs $3 \& 7$ ). The observed treatment differences in $g_{1}$ were not always explicable in terms of current leaf water status. Thus, at site 2 , plants at positions 2 and 3 had similar mid-day $\psi$ and $\psi_{p}$ (Fig. 5 b) yet stomata of the latter group closed to a greater extent as water stress increased (Fig. 6). Furthermore, there was little difference in the maximum total $g_{1}$ of moderately stressed plants at site I (minimum mid-day $\psi=-1.16$ $\left.\mathrm{MPa}, \psi_{\mathrm{p}}=0.1 \mathrm{MPa}\right)$ and that observed for more stressed plants at site 2, position I (minimum mid-day $\psi=-1.70 \mathrm{MPa}, \psi_{\mathrm{n}}=-0.12 \mathrm{MPa}$ ). Stomatal response may, therefore, have been partly conditioned by stress history. Previous stress treatment usually results in a reduction in stomatal sensitivity to water stress. This effect has usually been attributed to osmotic adjustment (Brown et al., 1976; Turner, Begg \& Tonnet, 1978), which implies that $g_{1}$ is more influenced by bulk leaf $\psi_{\mathrm{p}}$ than by $\psi$. Osmolic adjustment is, however, small in pearl millet (Henson e't al., 1982). Also, examination of the present data shows that the relationship between $g_{1}$ and $\psi_{\mathrm{p}}$ differed between sites, and suggests that some adaptation had occurred at site 2 permitting a higher $g_{1}$ to be achieved at a lower bulk leaf $\psi_{\mathrm{p}}$. This adaptation may have involved differences in solute accumulation at the level of the guard cells.

A further explanation for differences in stomatal behaviour, both between and within sites, is that a proportion of the more stressed plants were in the pre-flowering stage and their stomata may have been more sensitive to stress than were those of plants in full flower (Ackerson \& K reig. 1977: Ackerson. Kreig \& Sung, 1980: Morgan, 1977). This factor may also have accounted parly for the greater stomatal closure observed at all positions within the canopy for pholoperiodically-retarded plants as compared with flowering plants of the same age and mean $\psi$ ( $\mathrm{Fig} .8 \mathrm{c}$ ) (but see note above).

In the present study either the two leaf surfaces responded similarly to water stress (Fig. 6). or the sensitivity of the abaxial (lower) surface exceeded the adaxial (Fig. 2). In general, when greater abaxial than adaxial closure was observed. leaf $\psi_{\mathrm{P}}$ was $>-(0) 1$ $\mathrm{MPa}$ and $\psi>-1.5 \mathrm{MPa}$, while when both surfaces responded similarly to stress. $\psi_{\mathrm{r}}$ and $\psi$ were below these levels. Thus, closure of adaxial stomata appeared to be initiated at lower potentials than closure of abaxial stomata. These results contrast with previous reports (e.g. Kanemasu \& Tanner, 1969; Kassam, 1973: Sharpe, 1973; Brown et al., 1976; Turner at al.. 1978) of greater adaxial sensitivity to stress in other species. The reasons for the variation in relative response to water stress by the two surfaces in the different experiments with pearl millet are not clear. However, the greater opening of adaxial than abaxial stomata under water stress may have heen favoured by the upward folding of the leaf about the mid-rib, a characteristic of water-stressed millet. Leaf folding may have resulted in a more favourable micro-climate at the adaxial surface (e.g. lower lvpd), thus atcounting for the lower stress sensitivity of adaxial, compared with abaxial, stomata. Further work is required to resolve both this, as well as other questions raised by the present study.

\section{Acknowledgments}

We thank our colleagues R.B. Austin, P. Innes and S.A. Quarrie for critical comments on the manuscript, and members of the ICRISAT millet physiology programme for their help with the experiments. IEH is grateful to the UK Overseas Development Administration for financial support.

\section{References}

Ackerson, R.C. \& Krieg, D.R. (1977) Stomatal and non-stomatal regulation of water use in cotton, corn and sorghum Plant Physiologi, 60, 850)-853.

Acketson, R.C.., Krieg, D.R. \& Sung. F.J.M. (I980) I.cal conductance and osmoregulation of field-grown sorghum genolypes. Crop Science, 20, 1014.

Arnon. I. (1972) Crop Production in Dry Reguns. Vol. 2, $638 \mathrm{p}$ L.conard Hill, L.ondon.

Begg. J.E. (1965) The growth and development of a crop of bulrush millet (Pennisetum typhoides S. and H.) Journal of Agricullaral Scienre, 65, 341 349

Begg, J.F. \& Turner. N.C. (1970) Water potential gradients in field tobacco. Plant Physiology, 46, 343346.

Begg, J.E. \& Turner, N.C. (1976) (rop water deficits. Adnances in Agronomy, 28, 161217 
Begg, J.E., Bierhuizen, J.F., Lemon, E.R., Misra, D.K., Slatyer, R.O. \& Stern, W.R. (1964) Diurnal energy and water exchanges in bulrush millet in an area of high solar radiation. Agricultural Meteorology, 1, 294-312.

Biscoc. P.V., Cohen, Y. \& Wallace, J.S. (1976) Daily and seasonal changes of water potential in cereals. Philosophical Transactions of the Royal Society, London, Series B. 273, 565-580.

Black, C.R. \& Squirc, G.R. (1979) Effects of atmospheric saturation deficit on the stomatal conductance of pearl millet (Pennisetum typhoides S. and H.) and groundnut (Arachis hypogaea L.). Journal of Experimental Botany, 30, 935-945.

Brown, K.W., Jordan, W.R. \& Thomas, J.C. (1976) Water stress induced alteration in the stomatal response to leaf water potential. Physiologia Plantarum, 37, 1-5.

Catherinet, M.D., Dumont, S., Mayaki, A.A., Jacquin, B. \& Gaborit, J. (1963) Le mil et le sorgho dans l'agriculture du Niger. Agronomie Tropical'. 18, 108-125.

Cochemé, J. \& Franquin, P. (1967) An agroclimatology survey of a semi-arid area in Africa south of the Sahara. Tech. note no. 86 . 136 p. World Meteorological Organization.

Cowan, I.R. (1977) Stomatal behaviour and environment. In Advances in Botanical Research (eds R.D. Preston \& H.W. Woolhouse), Vol. 4, pp. 117-228. Academic Press, London.

Ferraris, R. (1973). Pearl Millet (Pennisetum typhoides). Review series I, Commonwealth Agricultural Bureau.

Gregory, P.J. (1979) Uptake of N, P and K by irrigated and unirrigated pearl millet (Pennisetum typhoides). Experimental Agriculture, 15, 217-223.

Gregory, P.J. \& Squire, G.R. (1979) Irrigation effects on roots and shoots of pearl millet (Pennisetum typhoides). Experimental Agriculture, 15, 161-168.

Hanks, R.J., Keller, J., Rasmussen, V.P. \& Wilson, G.D. (1976) Line source sprinkler for continuous variable irrigation-crop production studies. Soil Science Society of America Journal, 40, 426-429.

Henson, I.E., Mahalakshmi, V., Bidinger, F.R. \& Alagarswamy, G. (1981) Stomatal responses of pearl millet (Pennisetum americanum [L.] Leeke) genotypes, in relation to abscisic acid and water stress. Journal of Experimental Botany, 32, (in press).

Henson, I.E., Mahalakshmi, V., Bidinger, T.R. \& Alagarswamy, G. (1982) Osmotic adjustment to water stress in pearl millet (Pennisetum americanum [L.] Leeke) under field conditions. Plant, $\mathrm{Cell}$ and Environment, 5 (In press).

ICRISAT (Internationl Crops Research Institute for the Semi-Arid Tropics) (1977) Annual Report 1976-1977, Pp 61-62. Hyderabad, India.

ICRISAT (International Crops Research Institute for the Semi-Arid Tropics) (1978). Annual Report 1977-1978, Pp 183-184. Hyderabad, India.

ICRISAT (International Crops Research Institute for the Semi-Arid Tropics) (1980). Annual Report 1978-1979, Pp 69-71. India: ICRISAT, Patancheru, A.P. 502324.
Jones, H.G. (1977) Aspects of the water relations of spring wheat (Triticum aestivum $\mathbf{L}$.) in response to induced drought. Journal of Agricultural Science, 88, 267-282.

Kanemasu, E.T. \& Tanner, C.B. (1969) Stomatal diffusion sesistance of snap beans. 1. Influence of leaf-water potential.iplant Physiology, 44, 1547-1552.

Kassam, A.H. (1973) The influence of light and water deficit topon diffusive resistance of leaves of Vicia faba L. New Physiologist, 72, $557-570$.

Kaufmann, M.R. \& Hall, A.E. (1974) Plant-water balance-its relationship to atmospheric and edaphic conditions. Agricultural Meteorology, 14, 85-98.

McKree, K.J. (1974) Changes in the stomatal response characteristics of grain sorghum produced by water stress during growth. Crop Science, 14, 273-278

McPherson, H.G. \& Slatyer, R.O. (1973) Mechanisms regulating photosynthesis in Pennisetum typhoides. Australian Journal of Biological Science, 26, 329-339.

Morgan, J.M. (1977) Changes in diffusive conductance and water potential of wheat plants before and after anthesis. Australian Journal of Plant Physiology, 4, 75-86.

Raschke. K. (1975) Stomatal action. Annual Review of Plant Physiology, 26, 309-340.

Sharpe, P.J.H. (1973) Adaxial and abaxial stomatal resistance of cotton in the field. Agronomy Journal, 65, 570-574.

Sivakumar, M.V.K., Seetharama, N., Singh, S. \& Bidinger, F.R. (1979) Water relations, growth, and dry matter accumulation of sorghum under post-rainy season conditions. Agronomy Journal, 71, 843-847.

Squire, G.R. (1979) The response of stomata of pearl millet (Pennisetum typhoides S. and H.) to atmospheric humidity. Journal of Experimental Botany, 30, 925-933.

Turner, N.C. (1974a) Stomatal response to light and water under ficld conditions. In Mechanisms of Regulation of Plant Growth (eds R.L. Bieleski, A.R. Ferguson \& M.M. Cresswell), pp. 423-432. Bulletin no. 12, Royal Society, New Zealand.

Turner, N.C. (1974b) Stomatal behaviour and water status of maize, sorghum, and tobacco under field conditions. II. At low soil water potential. Plant Physiology, 53, 360-365.

Turner, N.C. \& Begg. J.E. (1973) Stomatal behaviour and water status of maize, sorghum, and tobacco under field conditions. I. At high soil water potential. Plant Physiology, 51, 31-36.

Turner, N.C., Begg, J.E. \& Tonnet, M.L. (1978) Osmotic adjustment of sorghum and sunflower crops in response to water deficits and its influence on the water potential at which stomata close. Australian Journal of Plant Physiology, 5, 597-608.

Tyree, M.T. (1976) Negative turgor in plant cells. Fact or fallacy? Canadian Journal of Botany, 54, 2738-2746.

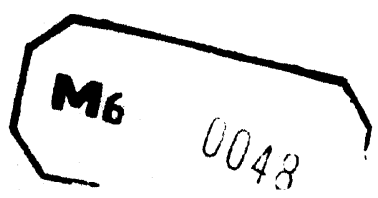

